Article

\title{
Evaluation of Environmental Moisture from NWP Models with Measurements from Advanced Geostationary Satellite Imager-A Case Study
}

\author{
Xiaowei Jiang ${ }^{1,2}$, Jun $\mathrm{Li}^{2, *}$, Zhenglong $\mathrm{Li}^{2}$, Yunheng Xue ${ }^{2,3}{ }^{\mathbb{D}}, \mathrm{Di} \mathrm{Di}^{4}$, Pei Wang ${ }^{2}$ and \\ Jinlong $\mathbf{L i}^{2}$ \\ 1 National Meteorological Information Centre, China Meteorological Administration, Beijing 100081, China; \\ jiangxw@cma.gov.cn \\ 2 Cooperative Institute for Meteorological Satellite Studies, University of Wisconsin-Madison, Madison, WI \\ 53706, USA; zli@ssec.wisc.edu (Z.L.); yxue44@wisc.edu (Y.X.); pei.wang@ssec.wisc.edu (P.W.); \\ jinlong.li@ssec.wisc.edu (J.L.) \\ 3 Institute of Atmospheric Physics, Chinese Academy of Sciences, Beijing 100029, China \\ 4 Nanjing University of Information Science and Technology, Nanjing 210044, China; didi@nuist.edu.cn \\ * Correspondence: jun.li@ssec.wisc.edu
}

Received: 27 December 2019; Accepted: 16 February 2020; Published: 18 February 2020

check for updates

\begin{abstract}
The distribution of tropospheric moisture in the environment is highly associated with storm development. Therefore, it is important to evaluate the uncertainty of moisture fields from numerical weather prediction (NWP) models for better understanding and enhancing storm prediction. With water vapor absorption band radiance measurements from the advanced imagers onboard the new generation of geostationary weather satellites, it is possible to quantitatively evaluate the environmental moisture fields from NWP models. Three NWP models-Global Forecast System (GFS), Unified Model (UM), Weather Research and Forecasting (WRF) - are evaluated with brightness temperature (BT) measurements from the three moisture channels of Advanced Himawari Imager (AHI) onboard the Himawari-8 satellite for Typhoon Linfa (2015) case. It is found that the three NWP models have similar performance for lower tropospheric moisture, and GFS has a smaller bias for middle tropospheric moisture. Besides, there is a close relationship between moisture forecasts in the environment and the tropical cyclone (TC) track forecasts in GFS, while regional WRF does not show this pattern. When the infrared and microwave sounder radiance measurements from polar orbit satellite are assimilated in regional WRF, it is clearly shown that the environment moisture fields are improved compared with that with only conventional data are assimilated.
\end{abstract}

Keywords: uncertainties of moisture fields; evaluation of NWP models; AHI; data assimilation; typhoon case study

\section{Introduction}

Atmospheric water vapor is one of the major contributors to the Earth's energy balance, severe weather forecasting and climate studies [1-4]. Tropospheric moisture distribution, advection and convection are often associated with severe storm occurrence and development $[5,6]$. The satellite-based water vapor (WV) absorption bands in the infrared (IR) spectral region can be used to determine the distribution of WV in the troposphere. In this spectral region, the atmosphere is quite opaque if WV is abundant, but transparent when the air is very dry. Therefore, the WV absorption IR bands can provide useful moisture information for improving weather monitoring, nowcasting, and numerical weather prediction (NWP) model-based forecasting. They can also be used for detecting 
tropospheric moisture features associated with low-level thermodynamic conditions and evaluation of NWP model performance.

Moisture information with high temporal (better than $10 \mathrm{~min}$ ) and spatial (better than $2 \mathrm{~km}$ ) resolutions, which was not available previously, now is available from the advanced imagers onboard the new generation of international geostationary (GEO) weather satellites. Those advanced imagers include the Advanced Himawari Imager (AHI) onboard Japanese Himawari-8/-9 satellites [7], the Advanced Baseline Imager (ABI) [8,9] onboard U.S. new generation of Geostationary Operational Environmental Satellite (GOES-R) series, beginning with GOES-16 launched on 19 November 2016, and the Advanced Geosynchronous Radiation Imager (AGRI) onboard the Chinese new generation of FengYun-4 series, beginning with FengYun-4A launched on 11 December $2016[10,11]$. Those advanced imagers onboard the new GEO satellites provide measurements of weather system, as frequently as every $30 \mathrm{~s}$ depending on the needs. Their measurements and products can improve tropical cyclone (TC) tracking and intensity forecasts, increase thunderstorm and tornado warning lead time, and provide data for long-term climate variability studies.

Many studies $[5,6,12,13]$ have shown that the atmospheric moisture in the environment is associated with storm development. Therefore, it is important to evaluate the uncertainty of moisture fields in the environment from NWP models for better characterizing the environmental moisture in order to improve storm prediction. The bias analysis is widely used in evaluation studies [2,14-16]. It is a very efficient way to provide quantitative estimate of the direction, magnitude and uncertainty of the error. An assessment based on bias analysis between moisture field in NWP models and observations from multiple WV bands of GEO satellite is performed in this study. Three related questions will be addressed:

1. How to evaluate moisture in the environment from NWP models using the new GEO satellite imager data?

2. How does satellite data assimilation (DA) improve the moisture forecasts in the environment?

3. How are the forecasts of moisture in the environment associated with TC's track and intensity forecasts in NWP models?

Typhoon Linfa (2015) is the selected case for this study. Linfa was a TC that influenced the northern Philippines, Taiwan and southern China in early July 2015. Figure 1a shows the full disk image from AHI/Himawari-8, with the typhoon Linfa indicated by the black box. In addition, the best track of Linfa is shown in Figure 1b. Linfa formed on July 1 over the Philippine Sea and then it moved erratically westward toward the Philippines, eventually arriving the island of Luzon on July 4. It started to get weak across the island but reorganized over the South China Sea on July 5 . Then, it turned northward and re-intensified in the next two days, but finally weakened as it curved to the northwest toward southern China and dissipated on July 10 in the west of Hong Kong. Linfa produced heavy rainfall and gusty winds that destroyed 288 homes over China. Damage in the country totaled \$284 million with one death.

In this study, three NWP models (GFS-global forecast system, UM-unified model, WRF-Weather Research and Forecasting) are used in the evaluation with brightness temperature (BT) measurements from three WV absorption bands of the AHI. The Typhoon Linfa (2015) case studies have been conducted to demonstrate the performance of the three NWP models and the correlation between moisture forecasts and TC forecasts.

Section 2 describes the data and methodology used in this study; Section 3 presents the evaluation analysis and results based on the case study; Section 4 gives discussions and future plans; summary and conclusions are shown in Section 5. 

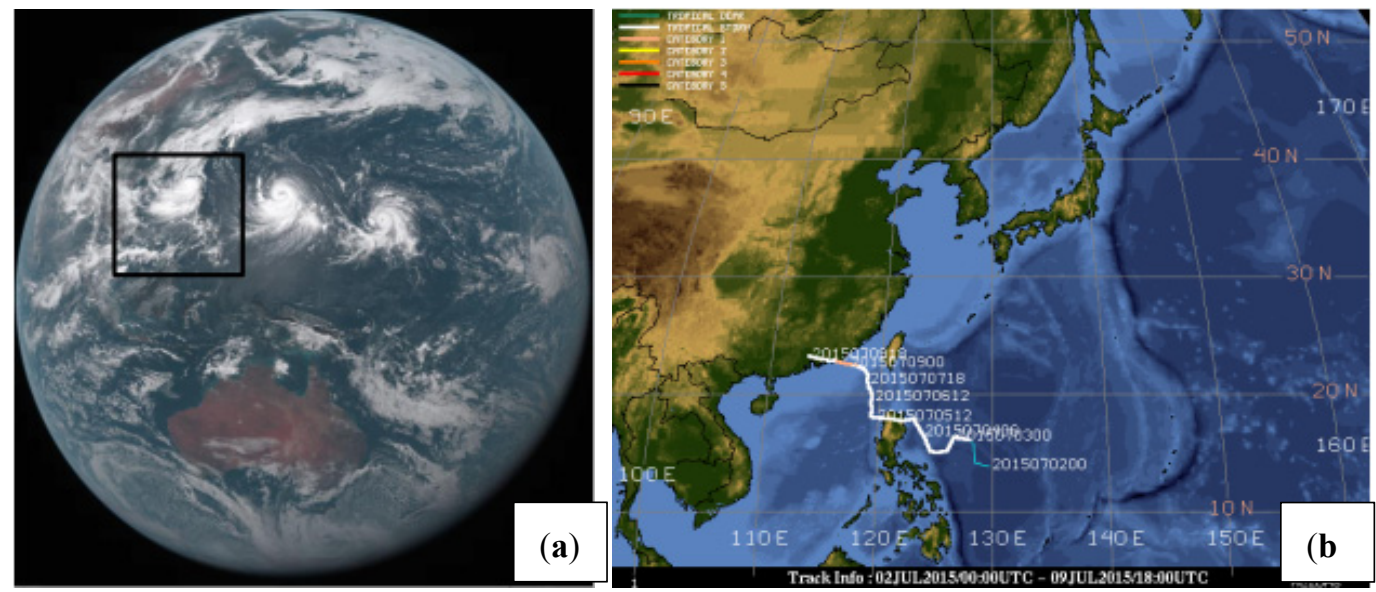

Figure 1. (a) Himawari-8 true-color Red/Green/Blue (RGB) full-disk image at 0340 UTC. The tropical cyclone in the black box is typhoon Linfa. (b) The best track of typhoon Linfa. Images from the Cooperative Institute for Meteorological Satellite Studies (CIMSS)/Space Science and Engineering Center (SSEC)/University of Wisconsin-Madison.

\section{Data and Methodologies}

\subsection{NWP Models}

The GFS Model was developed by the National Centers for Environmental Prediction (NCEP). Dozens of atmospheric and land-soil variables are available through this dataset. The entire globe is covered by GFS at a base horizontal resolution of $13 \mathrm{~km}$ for the first $240 \mathrm{~h}$ and $27 \mathrm{~km}$ from 240 to $384 \mathrm{~h}$, and vertical 64 levels for the whole $384 \mathrm{~h}$.

The UM is a numerical weather prediction and climate modeling software suite originally developed by United Kingdom Met Office. It is now both used and further developed by many weather-forecasting agencies around the world. It covers the entire globe and has approximately 16 $\mathrm{km}$ horizontal resolution and 70 vertical levels. And it provides boundary information for the now retired North Atlantic European (NAE) model.

The WRF is a mesoscale NWP system designed for both research and operational forecasting, which was developed by the National Center for Atmospheric Research (NCAR) and the National Oceanic and Atmospheric Administration (NOAA). It is a regional model configured with $12 \mathrm{~km}$ resolution and 51 vertical levels in this study. Some details for the three models used in this study are listed in Table 1.

Table 1. The numerical weather prediction (NWP) models evaluated in this study.

\begin{tabular}{|c|c|c|c|c|c|}
\hline NWP Models & Developed by & Domain & $\begin{array}{c}\text { Temporal } \\
\text { Resolution }\end{array}$ & $\begin{array}{l}\text { Horizontal } \\
\text { Resolution }\end{array}$ & $\begin{array}{c}\text { Vertical } \\
\text { Resolution }\end{array}$ \\
\hline GFS & NCEP & Global & $6 \mathrm{~h}$ & $\begin{array}{l}13 \mathrm{~km} \text { for the } \\
\text { first } 240 \mathrm{~h} \text { and } \\
27 \mathrm{~km} \text { from } 240 \\
\text { to } 384 \mathrm{~h}\end{array}$ & $\begin{array}{c}64 \text { levels } \\
\text { through } 384 \mathrm{~h}\end{array}$ \\
\hline UM & Met Office & & & $16 \mathrm{~km}$ & 70 levels \\
\hline WRF & NCAR, NOAA & Regional & & $12 \mathrm{~km}$ & 51 levels \\
\hline
\end{tabular}

Data from the World Meteorological Organization's (WMO) Global Telecommunication System (GTS) are also used in the WRF model in this study. GTS includes conventional data from global upper air and surface weather observations, which is composed of surface observations, radiosondes, wind 
profiles, and aircraft data. The report time intervals range from $1 \mathrm{~h}$ to $12 \mathrm{~h}$ and the available time is every $6 \mathrm{~h}$.

The Joint Polar Satellite System (JPSS) is the U.S. next generation of polar-orbiting environmental satellites. It is a collaborative effort between NOAA and the National Aeronautics and Space Administration (NASA). JPSS satellites observe the Earth from pole-to-pole orbits and can cross the equator 14 times daily in the afternoon orbit. They provide full global coverage twice a day and are critical component of the global observing system. The data and imagery obtained from satellite in the JPSS constellation will increase the timeliness and accuracy of the public warnings and weather forecasts. In this study, the data from the Suomi National Polar-orbiting Partnership (Suomi-NPP) satellite is assimilated into WRF to improve the medium and long-term weather predictions, especially the severe weather phenomena.

\subsection{AHI Data}

The Japanese Himawari-8 satellite was successfully launched into the geosynchronous orbit at $140^{\circ} \mathrm{E}$ on 17 October 2014 [14]. Himawari-8 is featured with the new 16-band Advanced Himawari Imager (AHI). The spatial resolution and observation frequency of Himawari-8 are also largely improved over those of its predecessor the Multi-functional Transport Satellite (MTSAT) series satellites. These improvements bring unprecedented levels of performance in nowcasting applications and short-range weather forecasting systems $[7,17,18]$. AHI is comparable to ABI onboard GOES-R series with the following functions: multi-band capacity, high spatial resolution, high temporal resolution and rapid scanning with flexible area selection [7]. AHI has 16 spectra bands in the visible (VIS) and IR spectrum. It is a significant increase in the number of spectral bands compared with heritage instruments. Its spatial resolution ranges from $0.5 \mathrm{~km}$ to $2 \mathrm{~km}$, depending on the spectral band. In this study, the spatial resolution of the three WV absorption bands is $2 \mathrm{~km}$. In each 10-min period, the AHI scans the full disk once and the limited areas in proportionally shorter intervals.

The WV (in terms of mixing ratio) Jacobian functions $\left(\frac{d T B}{d \ln q}\right)$ of the three AHI WV absorption bands used in this study are exhibited in Figure 2 using the U.S. 1976 standard atmosphere. The Jacobians denote the change of top-of-atmosphere (TOA) radiance in response to unit perturbation in atmosphere or surface, i.e., WV content in certain level. It is very important and useful in moisture profile retrieval and is able to reflect the remote sensing capability and limitation of the given spectral bands $[15,19,20]$. In Figure 2, the $6.25 \mu \mathrm{m}$ band (AHI, channel 8 ) detects WV at a higher atmospheric level around $300 \mathrm{hPa}$; the $6.95 \mu \mathrm{m}$ band (AHI, channel 9) peaks at a lower level around $350 \mathrm{hPa}$, whereas the $7.35 \mu \mathrm{m}$ band (AHI, channel 10) peaks at a lowest level around $480 \mathrm{hPa}$. The three WV absorption bands, together with other IR bands, provide total precipitable water (TPW), three layered precipitable water (LWP) and atmospheric instability indices that are very useful for real-time or near real-time (NRT) situation awareness and nowcasting applications [21].

Figure 3 shows the three WV absorption bands BT images for all skies (upper panel) and clear skies (lower panel) from AHI at 1800 UTC, 5 July 2015, indicating three TCs over Pacific Ocean including Typhoon Linfa. The Himawari-8 Cloud Mask Product [22] is used to filter out cloudy regions. Note that only the regions where the zenith angles are smaller than $67^{\circ}$ are chosen to apply the cloud detection. The three WV absorption bands reflect moisture distribution at three different atmospheric layers in TC environment, which are used in this study to evaluate the capability of NWP models on simulating the upper tropospheric moisture. 


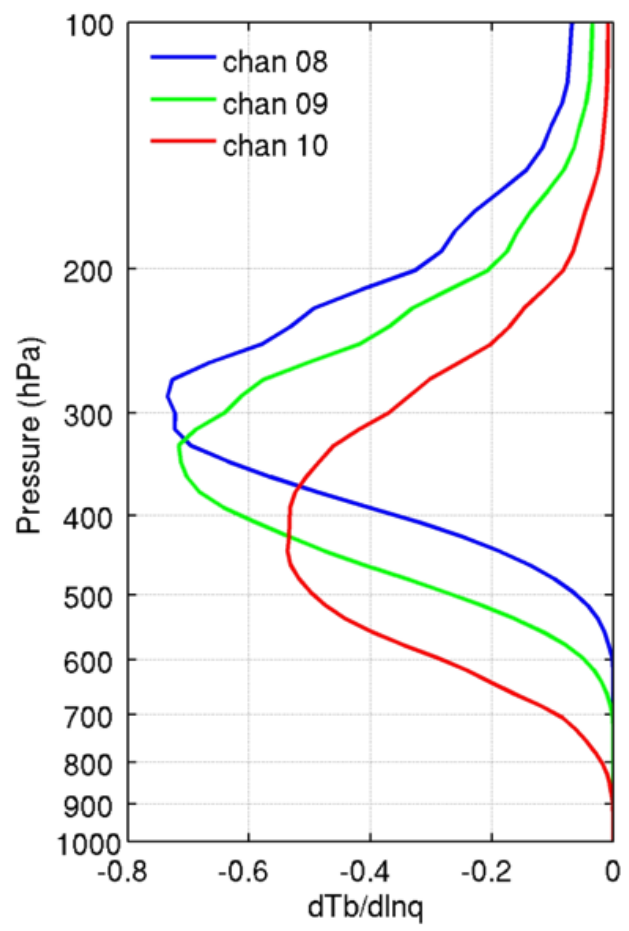

Figure 2. The water vapor (WV) Jacobian Function of Advanced Himawari Imager (AHI) calculated from a tropical atmospheric profile using the fast-radiative transfer model, hyperspectral infrared (IR) all-sky radiative transfer model (HIRTM).

Channel 8
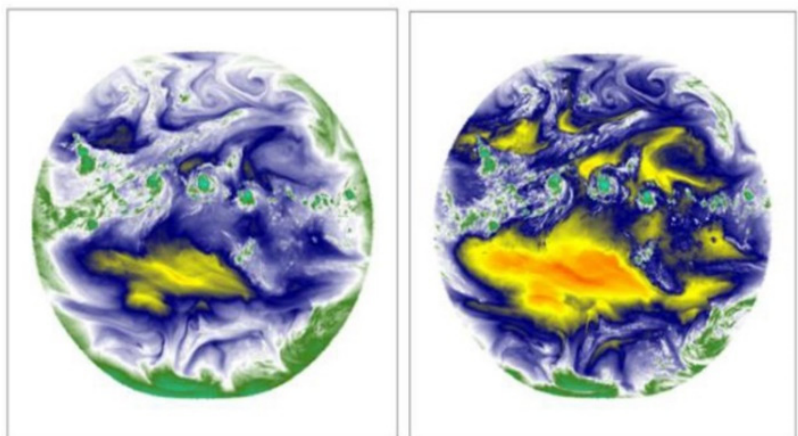

Channel 9

Channel 10

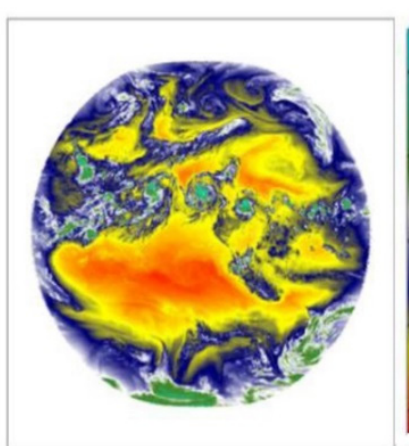

193

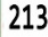

233

253

273
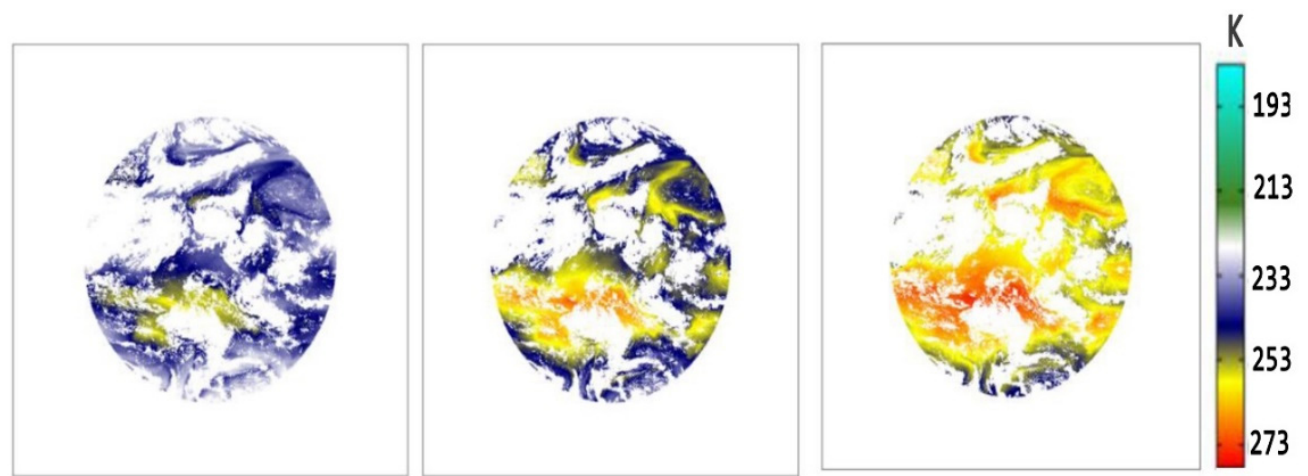

Figure 3. Brightness temperature (BT) images from three water vapor channels of AHI for (upper panel) all skies and (lower panel) clear skies on 5 July 2015 at 1800 UTC. The lower panels are limited to the satellite zenith angle of 67 degree. 


\subsection{Methodologies}

To evaluate the moisture information in different NWP models using BT measurements from three WV absorption bands of AHI, a model-to-radiance method is used in this study. NWP model outputs were converted to radiances using a fast-radiative transfer model (RTM), and then the radiances are further converted to BTs. The RTM used in this study is the hyperspectral IR all-sky radiative transfer model (HIRTM; [23]), which combines atmospheric transmittances caused by molecular absorption, cloud absorption and scattering from cloud hydrometeors [23]. 101-level atmospheric vertical profiles of WV concentration, temperature and ozone as well as cloud information (phase, cloud top pressure, and effective particle size, determined from hydrometer profiles) are used as the input for HIRTM, and the surface properties (such as surface temperature and pressure from NWP models, and surface IR emissivity from University of Wisconsin baseline fit emissivity database [24], satellite zenith and specific band information are also required for calculating the radiances (or BTs) and the Jacobian functions $[20,25]$. Note the accuracy of surface properties is not important for this typhoon case study because the environment is moist enough to be practically opaque to the surface contributions. Although HIRTM is developed for all-sky hyperspectral IR sounder radiance simulation, it can also be applied for broad band sensor IR band radiance calculations with appropriately applying the imager spectral response functions (SRFs) [26]. The simulated bands in this study are three AHI WV absorption bands (i.e., AHI channel 8 centered at $6.25 \mu \mathrm{m}$, channel 9 at $6.95 \mu \mathrm{m}$ and channel 10 at 7.35 $\mu \mathrm{m})$ from Himawari-8. The atmospheric profiles from different NWP models are all interpolated to the HIRTM's standard 101 atmospheric pressure levels using linear interpolation method [18] in the domain of logarithm of pressure.

It should be noted that this assessment is based on clear sky conditions because of the limitations in cloudy radiance simulation. For example, GFS and UM models do not provide hydrometer profile information as much as WRF model. It would be unfair for comparisons between the three models with different input of moisture information. Besides, the uncertainties in IR cloudy radiance simulation with RTM are much larger than those in clear sky. As a result, operational centers are only assimilating clear IR radiances into NWP models. Thus, it makes more sense to evaluate clear sky moisture at this moment.

Additionally, in order to assess the impact of assimilating satellite data on moisture simulation, the Gridpoint Statistical Interpolation (GSI) system version 3.1 from the Developmental Testbed Center (DTC) is used as the DA system for WRF model. It is a three-dimensional incremental variational (3D-Var) system for both global and regional NWP applications [27,28]. DTC transitioned the operational GSI system into a community system, which can be used in the public domain for study, research or other purposes. WRF/GSI together now is widely used in the research community [16,29-35].

\subsection{Sensitivity Study}

The BTs from the three WV absorption bands are sensitive to the atmospheric moisture as shown in Figure 2. While Figure 2 shows BT sensitivity to moisture change at each level, it is not intuitive how BT is sensitive to the overall moisture change. The BT sensitivity test is shown in Figure 4a,b, where $\delta B T=B T(q)-B T(q+\delta q)$. The standard tropical profile is used in this test. The change of whole moisture profile in percentage is used as an independent variable and the change of BT is the dependent variable. In the BT sensitivity tests of Figure $4, \delta q$ is varied from $0 \%$ to $\pm 50 \%$ with an interval of $5 \%$. 


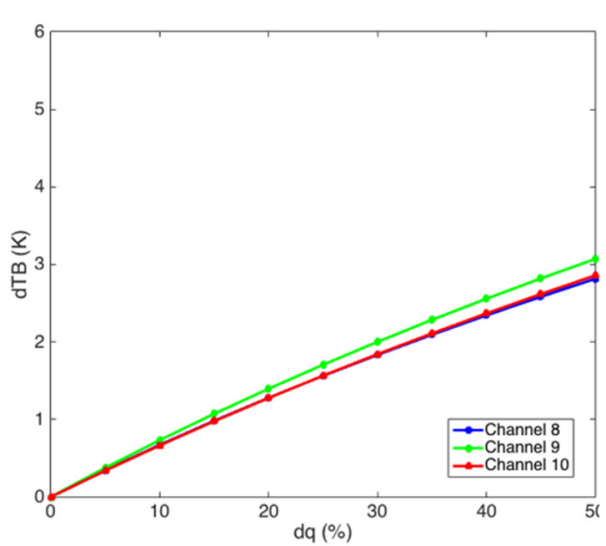

(a)

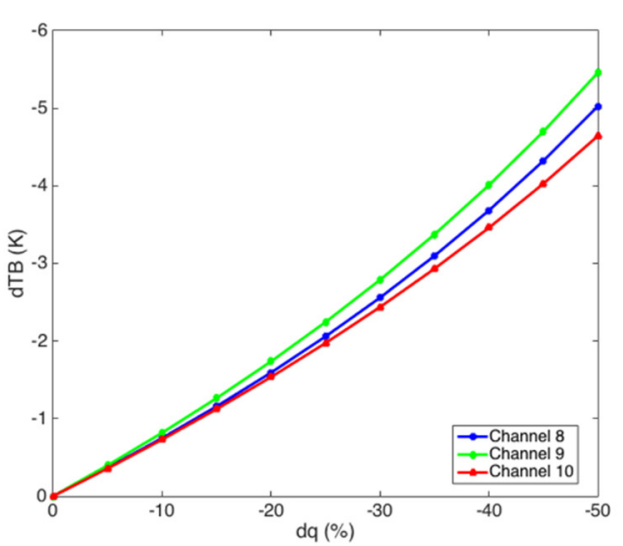

(b)

Figure 4. BT sensitivity to moisture with (a) increasing moisture from $0 \%$ to $50 \%$, and (b) decreasing moisture from $0 \%$ to $-50 \%$. Blue line is for AHI Channel 8, green line is for AHI Channel 9 and red line is for AHI Channel 10. A tropical atmospheric profile is used in the calculations.

In Figure 4, it is shown that the BT of AHI Channel 9 is slightly more sensitive to the change of moisture. Another interesting fact is that the BTs of all three WV absorption bands are more sensitive to the change of moisture when the environment is getting drier. This is because when the moisture is decreasing, the atmosphere is getting more transparent for IR radiance. The observed BT quickly increases due to less absorption by WV. However, when the moisture is increasing, more radiance is absorbed by WV, then the sensor onboard satellite receives less radiance, which appears as colder BT. In addition, when the moisture further increases, the atmosphere becomes saturated, and it leads to a smaller change in the BT reduction.

\section{Results}

\subsection{NWP Models Assessment}

\subsubsection{BT Differences between NWP Models and AHI WV Absorption Bands Observations}

To better evaluate the performance of these NWP models on the moisture forecast, the BT and BT difference (BTD) between models' calculations and AHI observations for three WV absorption bands at 1800 UTC on 5 July 2015 are shown in Figures 5-7 for clear skies. In this case, most of the BTD is between $-10 \mathrm{~K}$ and $10 \mathrm{~K}$. For Channel 8 (Figure 5), the range of BT is between $230 \mathrm{~K}$ and 250 K. Figure 3 shows that the region between the two typhoons (the left one is Linfa, the right one is Chan-hom), especially around typhoon Chan-hom, is warmer. Most of the BTD of GFS is negative, which means the environment forecast by GFS is wetter than the observations. For UM, the moisture forecast is mostly drier than the observation. For the moisture forecast of WRF (GTS only), it has the combination of drier and wetter environment-the parts around the typhoons are wetter such as the region around $23^{\circ} \mathrm{N}, 133^{\circ} \mathrm{E}$, and other parts are drier than the observations. 
GFS
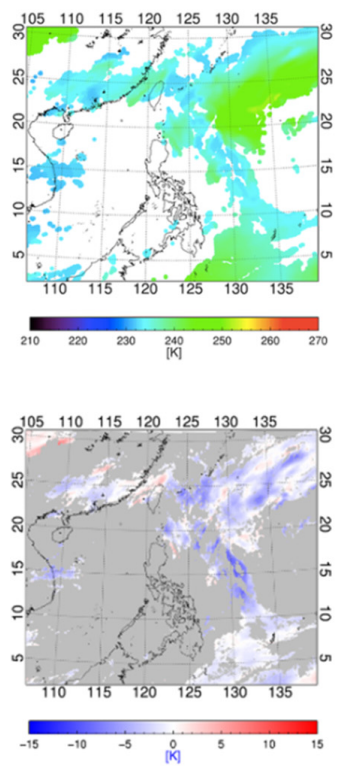

UM

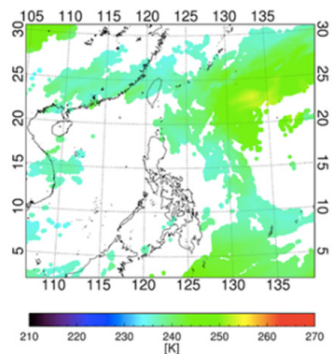

WRF(GTS only)

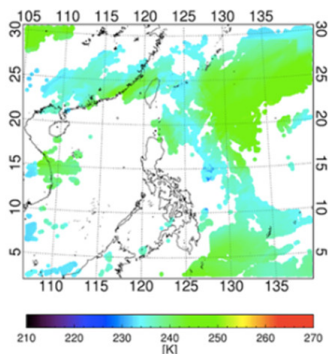

BTD $=$ model - Obs

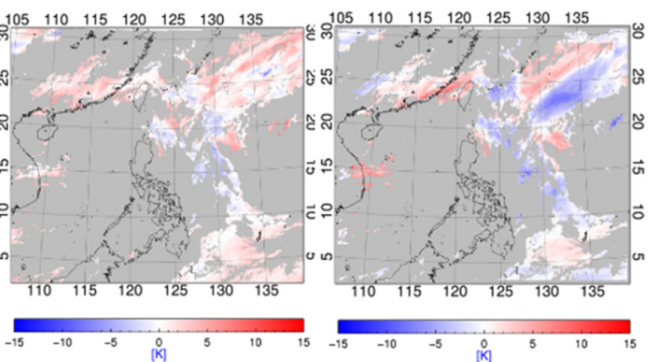

AHI Observation

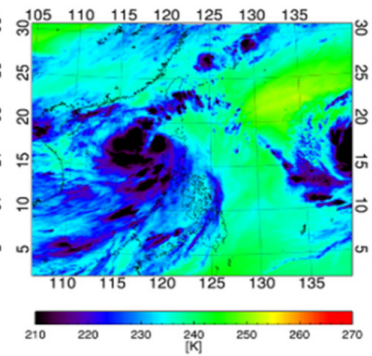

Figure 5. (upper right) AHI/Himawari-8 channel 8 BT measurements, (upper) calculated BTs from GFS, UM and WRF (GTS only) 12-h forecasts (07-05-2015 1800 UTC [06 UTC+12 h]), and (bottom) the corresponding BT difference (BTD; model - observation) using HIRTM. GFS = Global Forecast System; UM = Unified Model; WRF = Weather Research and Forecasting; GTS = Global Telecommunication System.

GFS
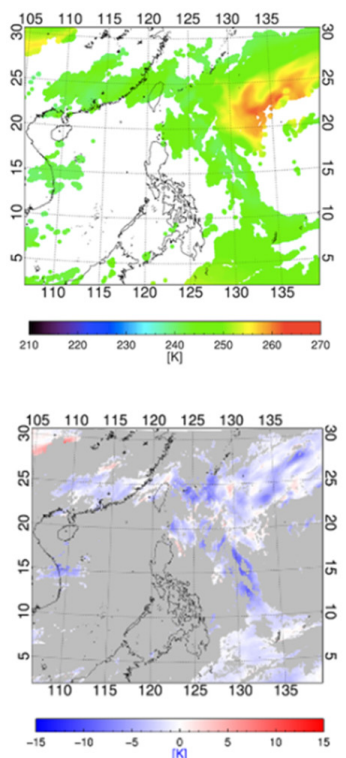

UM
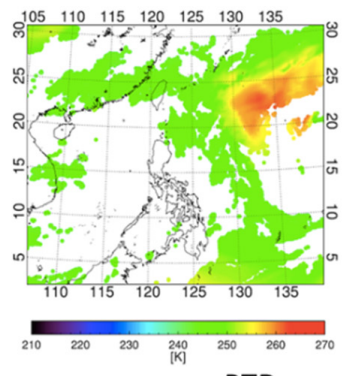

BTD $=$ model - Obs
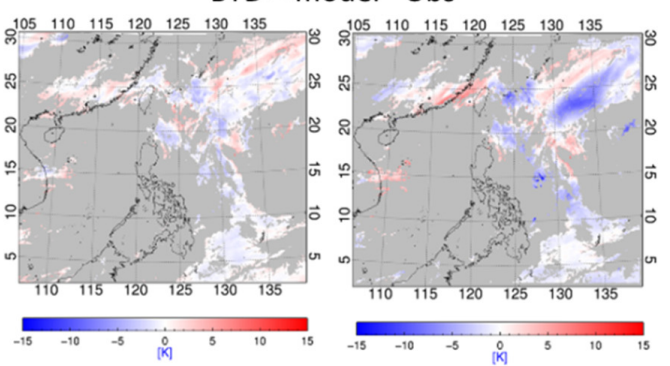

AHI Observation
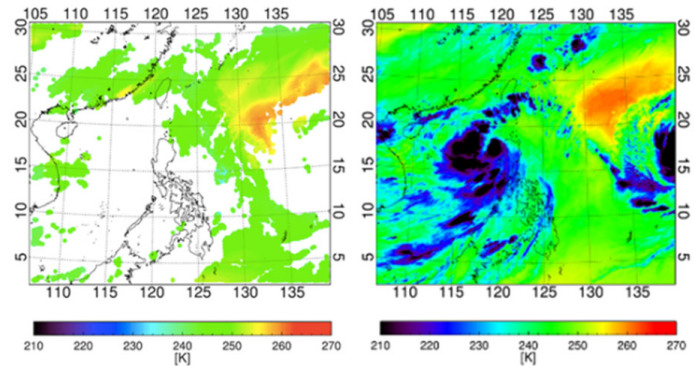

Figure 6. Same as Figure 5 but for AHI channel 9. 

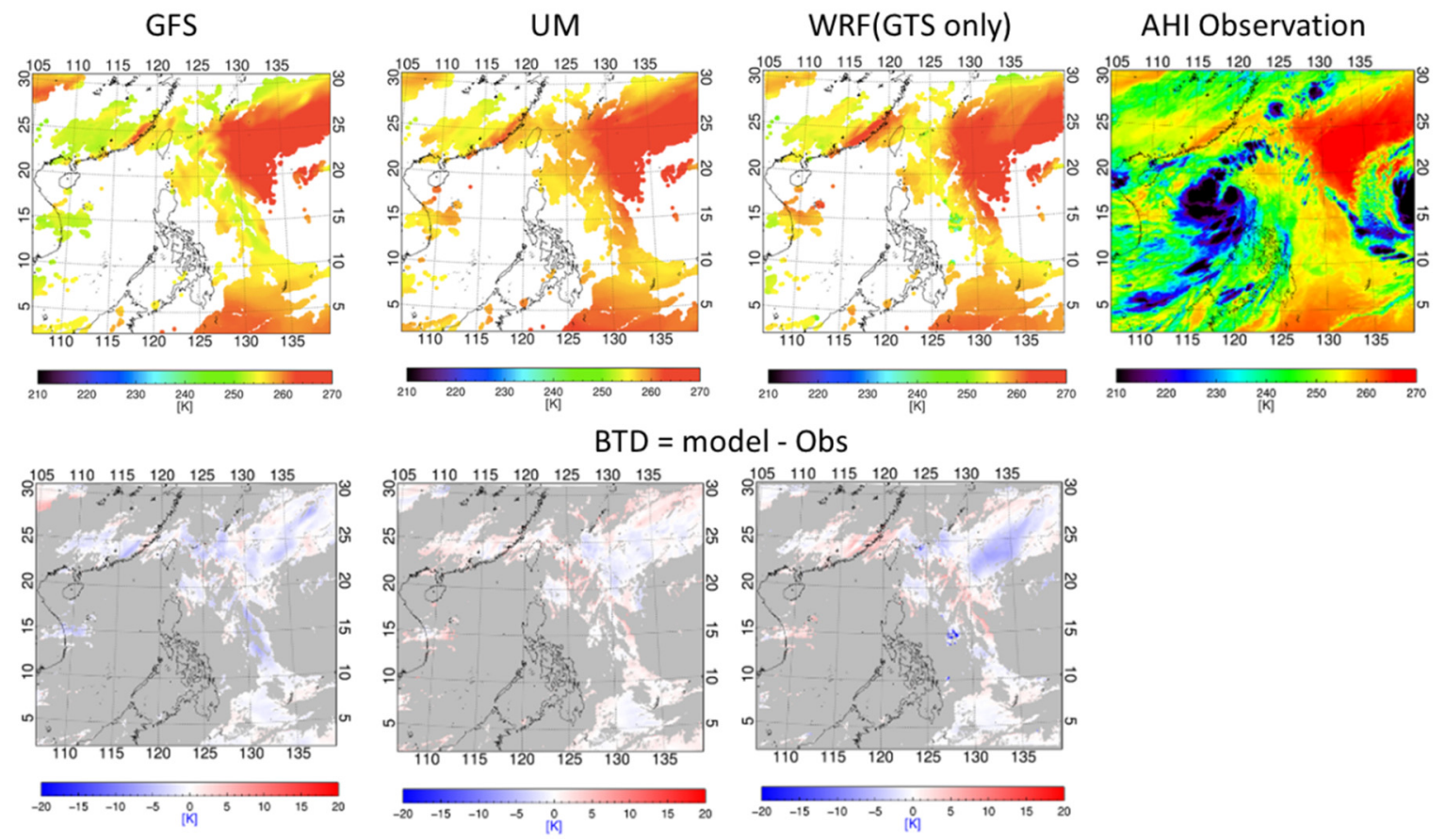

Figure 7. Same as Figure 5 but for AHI channel 10.

Similar results can also be seen in AHI Channel 9 and 10 in Figures 6 and 7, respectively. For Channel 9, most of the BTs are between $245 \mathrm{~K}$ and $265 \mathrm{~K}$. For Channel 10, the range of BT is between $250 \mathrm{~K}$ and $270 \mathrm{~K}$ and the range of BTD is between $-5 \mathrm{~K}$ and $5 \mathrm{~K}$. For all three models, the BTD of Channel 10 is smaller than that of the other two channels, which indicates that the performance of these models on the environmental moisture forecast in the mid-lower troposphere is better than that for the mid-upper troposphere in this particular case. In addition, the BTD of the UM model is the smallest among these three NWP models.

\subsubsection{Evaluation of Satellite Data Assimilation for Tropospheric Moisture Simulation}

Satellite data has been proven for their positive impact on NWP based forecasts [33,36,37]. To better understand the influence of satellite data such as the Cross-track Infrared Sounder (CrIS) and the Advanced Technology Microwave Sounder (ATMS) observations from JPSS using Suomi NPP on the moisture forecast, the BT and BTD between the model calculations from WRF (with GTS data only)/WRF (GTS and JPSS data) and AHI observations for three WV absorption bands at 1800 UTC on 5 July 2015 are shown in Figures 8-10. Assimilation of JPSS satellite data (CrIS and ATMS) provides some substantial improvements in moisture forecasts in all three WV absorption bands, especially for the region of $20^{\circ} \mathrm{N}-30^{\circ} \mathrm{N}, 120^{\circ} \mathrm{E}-140^{\circ} \mathrm{E}$. The statistical results of BTD in both WRF (with GTS only) and WRF (GTS + JPSS) are shown in Table ??. The mean and standard deviation of the BTD in the WRF (GTS + JPSS) have decreased in all three AHI channels when compared with the WRF (GTS data only). 

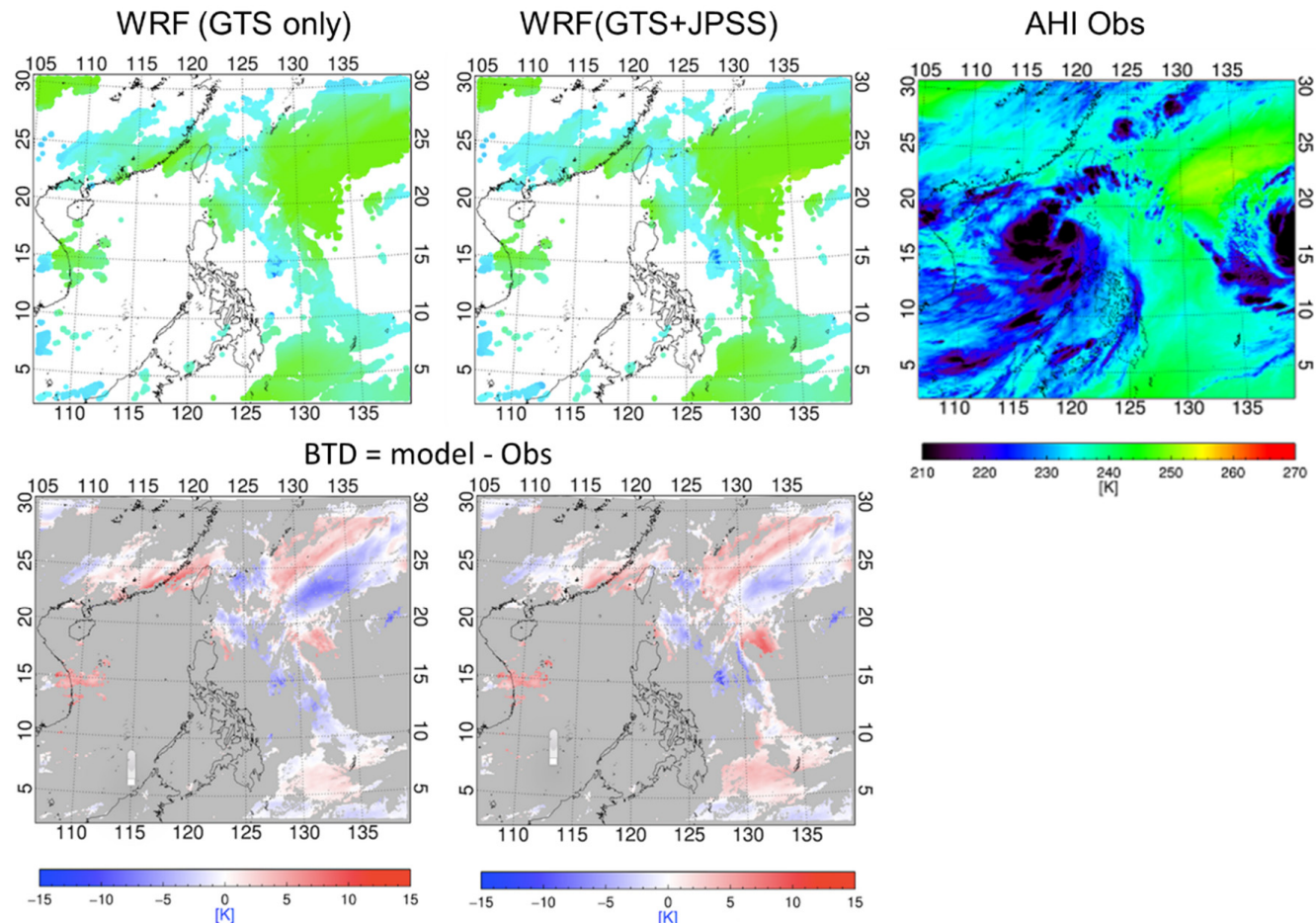

Figure 8. (upper right) AHI/Himawari-8 channel 8 BT measurements, (upper) calculated BTs from WRF (GTS only) and WRF (GTS+JPSS) 12-h forecasts (07-05-2015 1800 UTC [06 UTC+12 h]), and (bottom) the BTD (model—observation) using HIRTM. JPSS = Joint Polar Satellite System.

WRF (GTS only)

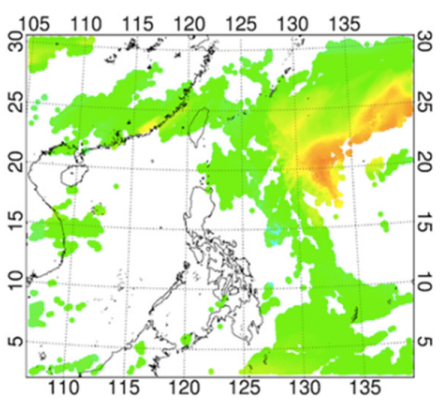

$$
\text { BTD }=\text { model }- \text { Obs }
$$
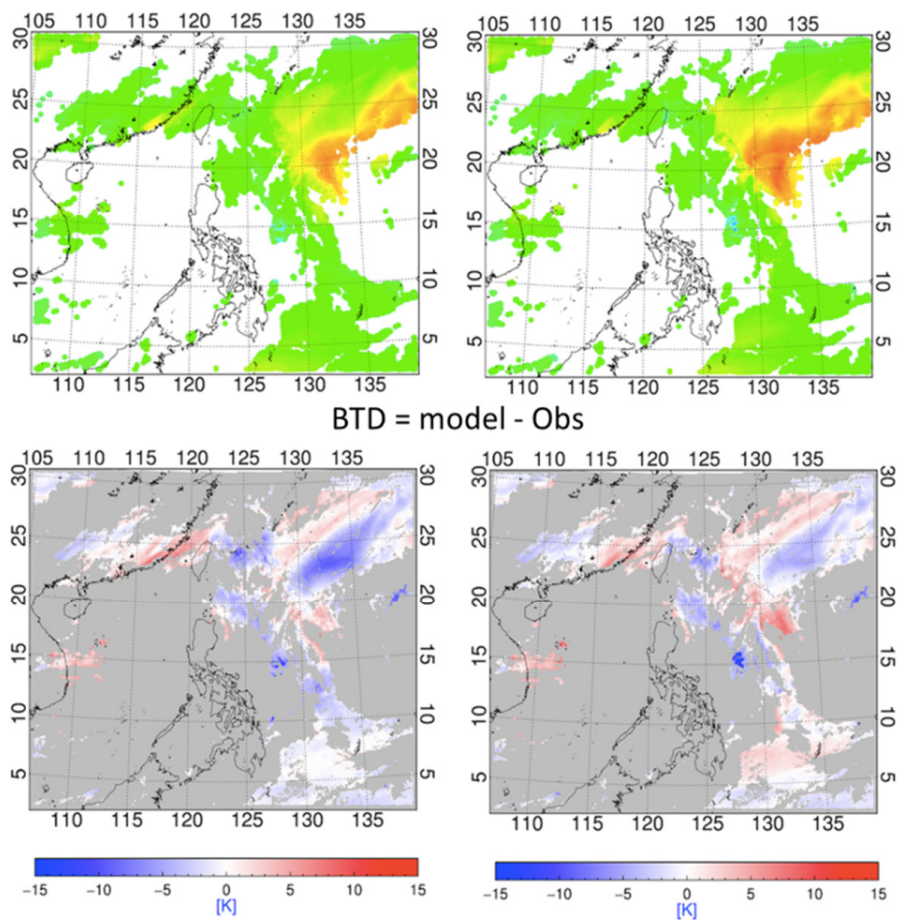

$\mathrm{AHI}$ Obs

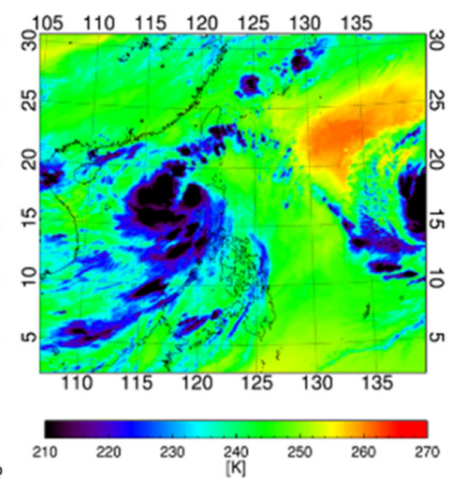

Figure 9. Same as Figure 8 but for AHI channel 9. 

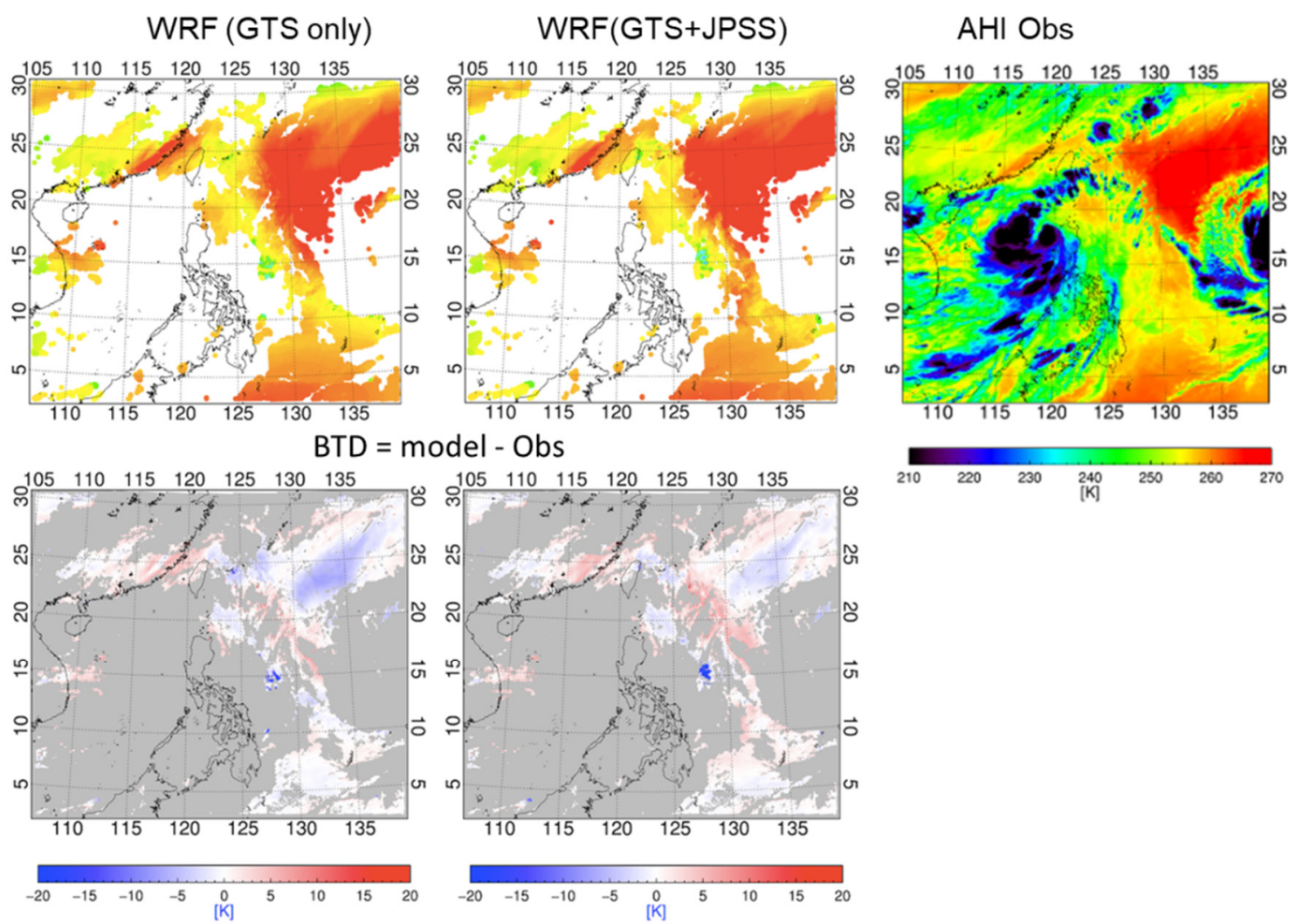

Figure 10. Same as Figure 8 but for AHI channel 10.

Table 2. Statistical results of BTD for WRF (GTS only) and WRF (GTS+JPSS) in three water vapor absorption bands for the 72-h forecast started from 1800 UTC 5 July 2015.

\begin{tabular}{|c|c|c|c|c|c|c|}
\hline \multirow{2}{*}{ (unit/K) } & \multicolumn{2}{|c|}{ Channel 8} & \multicolumn{2}{|c|}{ Channel 9} & \multicolumn{2}{|c|}{ Channel 10} \\
\hline & mean & STD & mean & STD & mean & STD \\
\hline WRF (GTS only) & -1.6862 & 2.685 & -1.6812 & 2.343 & -0.3773 & 1.9742 \\
\hline WRF(GTS+JPSS) & -0.9132 & 2.6005 & -1.5845 & 2.2406 & -0.2212 & 1.9506 \\
\hline
\end{tabular}

Figure 11 shows BTD between BT simulations from NWP models and AHI observations over clear skies for three WV absorption bands of 72-h forecasts started from 1800 UTC 5 July 2015. The BT simulations are calculated with model forecast (72-h forecast at each 6-h started from 1800 UTC 5 July 2015) and HIRTM. GFS always has a negative BT bias whereas UM always has positive BT bias. However, UM has an overall better performance with a smallest mean bias of the three WV absorption bands. For WRF model, assimilation of JPSS satellite data (including GTS) can decrease some BT bias when compared with assimilation of GTS data only. Both WRF (GTS only) and WRF (GTS+JPSS) have smaller BT bias than GFS and UM for most of time before $36 \mathrm{~h}$, but the BT biases of these two regional forecasts become larger than those from the two global models after $36 \mathrm{~h}$. 
Brightness Temperature Bias from 07-05-2015 1800 UTC [72h]
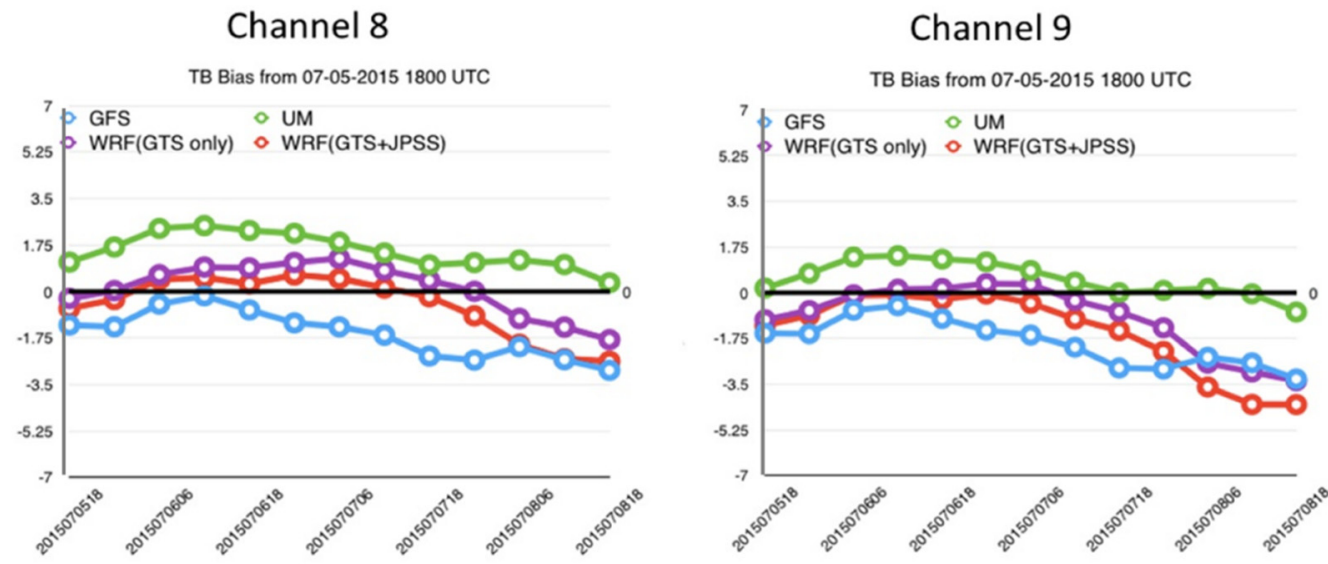

Channel 10

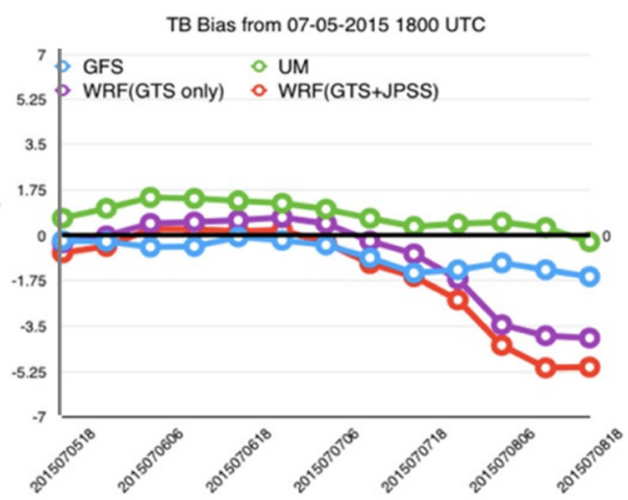

Figure 11. Time series of BT bias between models calculations (from GFS, UM, WRF (GTS only) and WRF (GTS+JPSS)) and AHI observations for the three WV absorption bands of 72-h forecasts started from 1800 UTC 5 July 2015. The x-axis represents for the forecast time (unit: UTC) and y-axis represents for the BT bias (unit: K).

\subsection{Relations between the Moisture Forecast Bias and the TC Forecast Bias}

Track and intensity (characterized by maximum wind speed) are two important parameters for TC forecasts. The impacts from the moisture environment on the hurricane track and intensity forecasts are discussed in this section. As shown in Figure 12, the GFS and WRF (GTS+JPSS) are better in the forecast of TC with smaller track and intensity root mean square error (RMSE) than UM and WRF (GTS only), respectively. Therefore, only the global model GFS and the regional model WRF (GTS+JPSS) are selected for the following analysis. The association between BT bias and track bias of the three WV absorption bands is shown in Figure 13. The same case in Figure 11 is used (e.g., the BT bias in the environment and track bias are calculated from 6-h, 12-h, 18-h, 24-h, 30-h, 36-h, 42-h, 48-h, 54-h, 60-h, 66-h and 72-h forecasts in the scatterplot). The polynomial model is chosen as the fitting method. It is shown that the regional model has smaller track bias than the global model in this case. Figure 13 shows that the track bias appears to have a positive correlation with the BT bias for GFS forecast, which is not obvious for WRF (GTS+JPSS) model in this particular case. Therefore, improving the environmental moisture forecasts may have a positive impact on the track forecasts for the GFS model but may not for WRF model. 


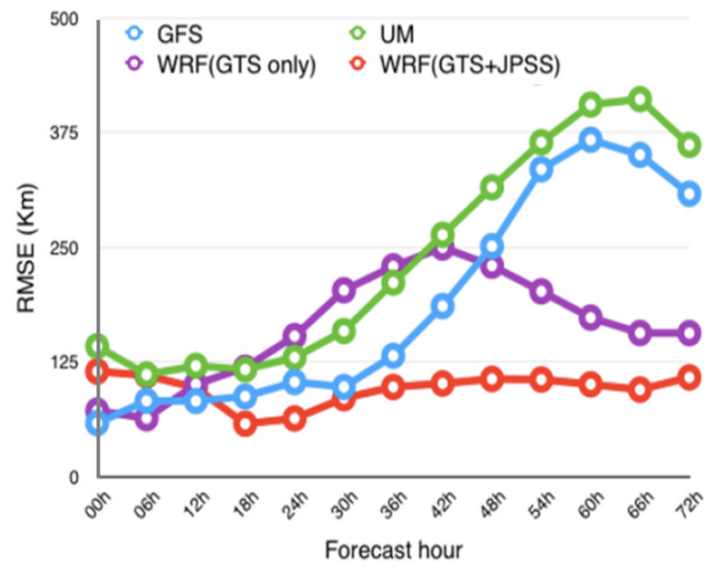

(a)

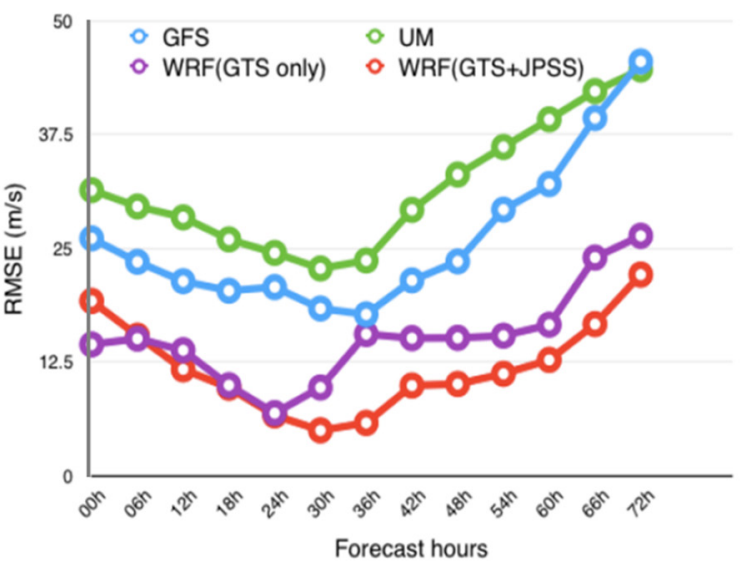

(b)

Figure 12. Root mean square error (RMSE) of (a) track $(\mathrm{km})$ and $(\mathbf{b})$ intensity (characterized by maximum wind speed, $\mathrm{m} / \mathrm{s}$ ) between the Japan Meteorological Administration (JMA) best track data for typhoon Linfa (2015) and the $72 \mathrm{~h}$ forecasts (started from Jul-05-2015 1800 UTC) from GFS, UM, WRF (GTS only) and WRF (GTS+JPSS).
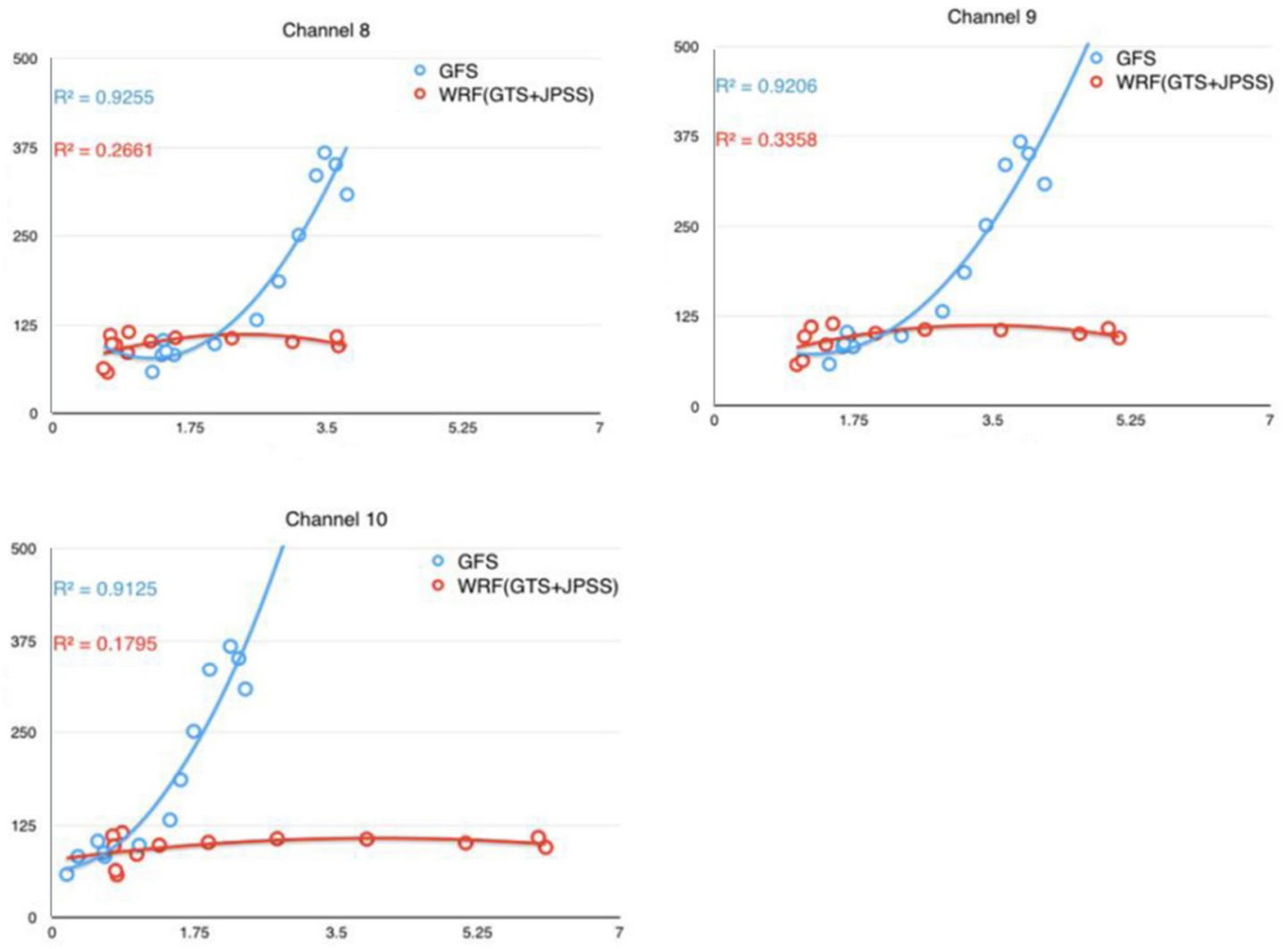

Figure 13. The correlation between moisture forecast bias (absolute value) and track forecast bias of GFS (blue line) and WRF with conventional data and JPSS satellite data assimilation (red line) for three WV absorption bands. The x-axis represents for the brightness temperature bias (unit: K) and y-axis represents for the track bias (unit: $\mathrm{km}$ ).

Figure 14 shows the intensity bias versus the BT bias of the three WV absorption bands. GFS and WRF with JPSS data assimilation are chosen again to illustrate the possible relationship between the moisture forecast and the intensity forecast. Similar to the track forecast bias, the regional model 
has a smaller intensity bias than the global model. The relationship between the moisture bias and the intensity bias is not as obvious as that between the moisture bias and the track bias, but the smaller intensity bias still tends to occur with the smaller BT bias especially for GFS model. Therefore, improving the forecasts of the moisture environment should also improve the typhoon intensity forecast for the GFS model, which is also found in recent studies [33,37]. Moreover, Figure 13 together with Figure 14 indicates that the track is easier to be improved than the intensity with more accurate moisture forecasts.
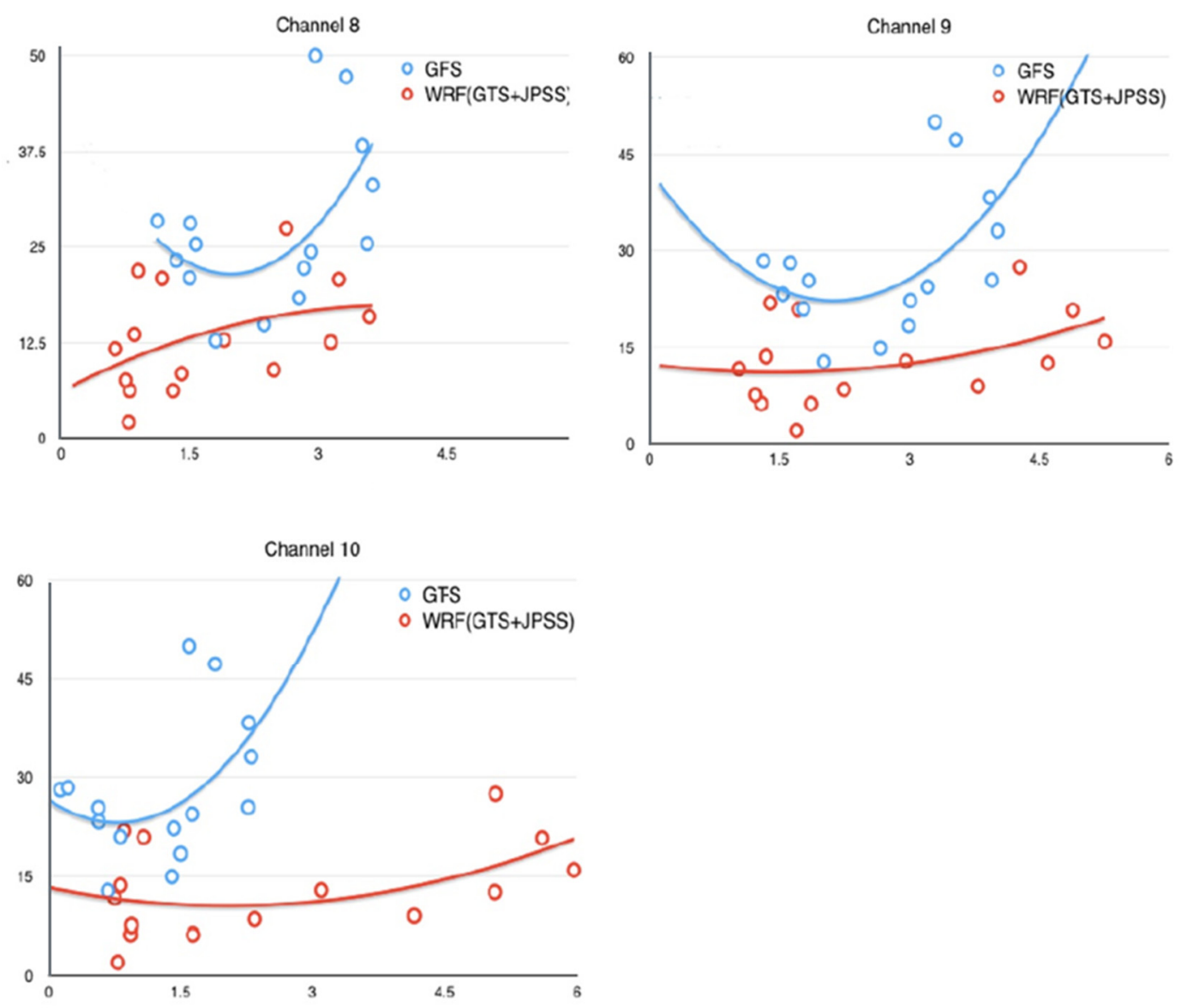

Figure 14. Same as Figure 13 but the y-axis is for intensity bias.

There are several possible reasons why GFS seems have a positive correlation between the moisture forecast biases and the TC forecast biases especially for track forecasts, while WRF does not show. GFS is a global model controlled by large-scale temperature and moisture environment, so a good moisture field could result in a good prediction forecast. However, the regional model might be controlled by the mesoscale features, especially the microphysics schemes and dynamic conditions such as wind field. In such a way, the moisture environment might not have such an obvious impact on the typhoon track. Another possible reason is, in this particular case, the track bias and intensity bias of the WRF model are much smaller than global models, especially with JPSS satellite data assimilated, so the improvement is not significant when the moisture field is getting better.

\section{Discussion}

This evaluation work is mainly based on a Typhoon case study. A model-to-radiance approach is applied to avoid the retrieval errors and to better use the radiance (or BT) measurements from satellites. What is unique of this study is that the three WV absorption bands of AHI, which represent the moisture field over three different layers of atmosphere, are used as reference data. It is found 
that three NWP models all show similar BT patterns with AHI observations. However, a wet bias is widely distributed in these models especially in AHI channel 9 and channel 10, which is consistent with previous studies [38,39]. For example, Chung et al. 2011 [38] found an averaged BT bias of -6 K in the Geophysical Fluid Dynamics Laboratory (GFDL) Atmospheric Model 2 (AM2) in comparison to the clear-sky BT of HIRS 6.7 um WV absorption band for the period of 1979-1999. However, those studies are usually limited to one WV absorption band. It is shown in this study that the same NWP model does show different performance in different WV absorption bands. Moreover, the moisture forecast from three NWP models in AHI Channel 10 is better than that in the other two channels. The relationship between moisture forecast bias and TC forecast bias is explored for a selected global model and regional model, respectively. The results show that improved forecasts of environmental moisture should lead to an improved track forecasts in TC, especially for the global GFS model. However, this tendency is not as obvious for the intensity forecast. This is probably because the intensity forecast is largely driven by storm-scale processes especially in the inner core of the storm [40]. This part of work is not to give a statistically reliable result with the limited data, but to qualitatively reveal the association between the moisture in the environment and TC's track and intensity forecasts in NWP models. Since this study is based on a typical typhoon case, for the future research plan, NWP model evaluation using AHI for longer time period (e.g., 1 year) will be carried out for generating statistically significant results, which will be useful for improving NWP models, correcting model bias, and improving satellite DA. Additionally, evaluation of next generation of global forecast modeling like GFS-FV3 (FV3 stands for Finite-Volume Cubed-Sphere dynamical core) using ABI over North America is also an ongoing effort at the Cooperative Institute for Meteorological Satellite Studies (CIMSS). For evaluation of global NWP models (GFS, UM, etc.), ideally, homogenized global WV absorption band radiances from international geostationary satellites are needed [41].

\section{Conclusions}

This study developed a methodology using AHI data to evaluate environmental moisture from NWP models. From this case demonstration, we found that:

- From the BT sensitivity test, the BTs of all three WV absorption bands are more sensitive when moisture is getting drier, as well as the BTs will change slowly when the atmosphere becomes more saturated.

- In this case, by comparing the BTDs from NWP models (GFS, UM, WRF (GTS only) and WRF (GTS+JPSS)), it shows that the UM model has an overall better environmental moisture forecast, especially over the mid-lower troposphere (for channels 9 and 10). With additional satellite data assimilated (results from regional WRF with JPSS), more accurate environmental moisture forecasts can be obtained.

- For the track and intensity forecasts of TC, in general, regional models have smaller track and intensity bias than global models. The performance of the regional models is better than the global models for the track forecast, especially after $24 \mathrm{~h}$ in this particular case. For the intensity forecasts, the regional models are comparable to the global models.

- From the relationship between environmental moisture forecast bias and track forecast bias, it is clear that a smaller moisture bias tends to result in a smaller track bias of TC, especially in the GFS model.

In summary, high temporal and spatial resolution of the tropospheric moisture information from the new generation of geostationary weather satellites is very useful for assessment of NWP models and improving moisture assimilation for high impact weather (HIW) forecasts.

Author Contributions: Conceptualization, J.L. (Jun Li); methodology, X.J. and J.L. (Jun Li); software, X.J.; validation, X.J., Y.X., D.D., P.W., and J.L. (Jinlong Li); formal analysis, X.J., Y.X., D.D., P.W., and J.L. (Jinlong Li); investigation, X.J., Y.X., D.D., P.W., and J.L. (Jinlong Li); resources, J.L. (Jun Li); data curation, Z.L.; writing-original draft preparation, X.J.; writing - review and editing, J.L. (Jun Li), Z.L., Y.X., and D.D.; visualization, X.J.; supervision, J.L. 
(Jun Li); project administration, Z.L.; funding acquisition, Z.L. All authors have read and agreed to the published version of the manuscript.

Funding: This work was supported in part by National Natural Science Foundation (No. 41775045, 41975020) and in part by GOES-R science program (NA15NES4320001).

Acknowledgments: AHI data are obtained from SSEC data center (https://www.ssec.wisc.edu/datacenter/), GFS data are obtained from NOAA NCEP (https://www.ncdc.noaa.gov/data-access/model-data/model-datasets/globalforcast-system-gfs), UM data are obtained from U.K. MetOffice (https://www.metoffice.gov.uk/research/approach/ modelling-systems/unified-model/index).

Conflicts of Interest: The authors declare no conflict of interest.

\section{References}

1. Trenberth, K.E.; Fasullo, J.T.; Kiehl, J. Earth's Global Energy Budget. Bull. Am. Meteorol. Soc. 2009, 90, 311-324. [CrossRef]

2. Soden, B.J.; Held, I.M. An Assessment of Climate Feedbacks in Coupled Ocean-Atmosphere Models. J. Clim. 2006, 19, 3354-3360. [CrossRef]

3. Pierrehumbert, R.T. The hydrologic cycle in deep-time climate problems. Nature 2002, 419, 191-198. [CrossRef] [PubMed]

4. Held, I.M.; Soden, B.J. Water vapor feedback and global warming. Annu. Rev. Energy Environ. 2000, 25, 441-475. [CrossRef]

5. Li, J.; Li, J.; Otkin, J.; Schmit, T.J.; Liu, C.-Y. Warning information in a preconvection environment from the geostationary advanced infrared sounding system-A simulation study using the IHOP case. J. Appl. Meteorol. Climatol. 2011, 50, 776-783. [CrossRef]

6. Li, J.; Liu, C.-Y.; Zhang, P.; Schmit, T.J. Applications of full spatial resolution space-based advanced infrared soundings in the preconvection environment. Weather Forecast. 2012, 27, 515-524. [CrossRef]

7. Bessho, K.; Date, K.; Hayashi, M.; Ikeda, A.; Imai, T.; Inoue, H.; Kumagai, Y.; Miyakawa, T.; Murata, H.; Ohno, T.; et al. An Introduction to Himawari-8/9-Japan's New-Generation Geostationary Meteorological Satellites. J. Meteorol. Soc. Jpn. Ser. II 2016, 94, 151-183. [CrossRef]

8. Schmit, T.J.; Gunshor, M.M.; Menzel, W.P.; Gurka, J.J.; Li, J.; Bachmeier, A.S. Introducing the next-generation Advanced Baseline Imager on GOES-R. Bull. Am. Meteorol. Soc. 2005, 86, 1079-1096. [CrossRef]

9. Schmit, T.J.; Griffith, P.; Gunshor, M.M.; Daniels, J.M.; Goodman, S.J.; Lebair, W.J. A closer look at the ABI on the GOES-R series. Bull. Am. Meteorol. Soc. 2017, 98, 681-698. [CrossRef]

10. Yang, J.; Zhang, Z.; Wei, C.; Lu, F.; Guo, Q. Introducing the new generation of Chinese geostationary weather satellites, Fengyun-4. Bull. Am. Meteorol. Soc. 2017, 98, 1637-1658. [CrossRef]

11. Min, M.; Wu, C.; Li, C.; Liu, H.; Xu, N.; Wu, X.; Chen, L.; Wang, F.; Sun, F.; Qin, D. Developing the science product algorithm testbed for Chinese next-generation geostationary meteorological satellites: Fengyun- 4 series. J. Meteorol. Res. 2017, 31, 708-719. [CrossRef]

12. Folland, C.K.; Palmer, T.N.; Parker, D.E. Sahel rainfall and worldwide sea temperatures, 1901-1985. Nature 1986, 320, 602. [CrossRef]

13. Sud, Y.C.; Smith, W.E. Influence of Local Land-Surface Processes on the Indian Monsoon: A Numerical Study. J. Clim. Appl. Meteorol. 1985, 24, 1015-1036. [CrossRef]

14. Da, C. Preliminary assessment of the Advanced Himawari Imager (AHI) measurement onboard Himawari-8 geostationary satellite. Remote Sens. Lett. 2015, 6, 637-646. [CrossRef]

15. Li, J.; Wolf, W.W.; Menzel, W.P.; Zhang, W.; Huang, H.-L.; Achtor, T.H. Global soundings of the atmosphere from ATOVS measurements: The algorithm and validation. J. Appl. Meteorol. 2000, 39, 1248-1268. [CrossRef]

16. Wang, P.; Li, J.; Li, J.; Li, Z.; Schmit, T.J.; Bai, W. Advanced infrared sounder subpixel cloud detection with imagers and its impact on radiance assimilation in NWP. Geophys. Res. Lett. 2014, 41, 1773-1780. [CrossRef]

17. Lee, Y.-K.; Li, J.; Li, Z.; Schmit, T. Atmospheric temporal variations in the pre-landfall environment of typhoon Nangka (2015) observed by the Himawari-8 AHI. Asia-Pac. J. Atmos. Sci. 2017, 53, 431-443. [CrossRef]

18. Liu, Z.; Min, M.; Li, J.; Sun, F.; Di, D.; Ai, Y.; Li, Z.; Qin, D.; Li, G.; Lin, Y. Local Severe Storm Tracking and Warning in Pre-Convection Stage from the New Generation Geostationary Weather Satellite Measurements. Remote Sens. 2019, 11, 383. [CrossRef] 
19. Bai, W.; Wu, C.; Li, J.; Wang, W. Impact of Terrain Altitude and Cloud Height on Ozone Remote Sensing from Satellite. J. Atmos. Ocean. Technol. 2014, 31, 903-912. [CrossRef]

20. Di, D.; Ai, Y.; Li, J.; Shi, W.; Lu, N. Geostationary satellite-based $6.7 \mu \mathrm{m}$ band best water vapor information layer analysis over the Tibetan Plateau. J. Geophys. Res. Atmos. 2016, 121, 4600-4613. [CrossRef]

21. Schmit, T.J.; Li, J.; Lee, S.J.; Li, Z.; Dworak, R.; Lee, Y.-K.; Bowlan, M.; Gerth, J.; Martin, G.D.; Straka, W. Legacy atmospheric profiles and derived products from GOES-16: Validation and applications. Earth Space Sci. 2019, 6, 1730-1748. [CrossRef]

22. Imai, T.; Yoshida, R. Algorithm theoretical basis for Himawari-8 cloud mask product. Meteorol. Satell. Cent. Tech. Note 2016, 61, 1-17.

23. Li, J.; Li, Z.; Wang, P.; Schmit, T.J.; Bai, W.; Atlas, R. An efficient radiative transfer model for hyperspectral IR radiance simulation and applications under cloudy-sky conditions. J. Geophys. Res. Atmos. 2017, 122, 7600-7613. [CrossRef]

24. Seemann, S.W.; Borbas, E.E.; Knuteson, R.O.; Stephenson, G.R.; Huang, H.-L. Development of a global infrared land surface emissivity database for application to clear sky sounding retrievals from multispectral satellite radiance measurements. J. Appl. Meteorol. Climatol. 2008, 47, 108-123. [CrossRef]

25. Di, D.; Li, J.; Han, W.; Bai, W.; Wu, C.; Menzel, W.P. Enhancing the Fast Radiative Transfer Model for FengYun-4 GIIRS by Using Local Training Profiles. J. Geophys. Res. Atmos. 2018, 123, 12,583-12,596. [CrossRef]

26. Di, D.; Min, M.; Li, J.; Gunshor, M.M. The Radiance Differences between Wavelength and Wavenumber Spaces in Convolving Hyperspectral Infrared Sounder Spectrum to Broadband for Intercomparison. Remote Sens. 2019, 11, 1177. [CrossRef]

27. Kleist, D.T.; Parrish, D.F.; Derber, J.C.; Treadon, R.; Wu, W.-S.; Lord, S. Introduction of the GSI into the NCEP global data assimilation system. Weather Forecast. 2009, 24, 1691-1705. [CrossRef]

28. Wu, W.-S.; Purser, R.J.; Parrish, D.F. Three-dimensional variational analysis with spatially inhomogeneous covariances. Mon. Weather Rev. 2002, 130, 2905-2916. [CrossRef]

29. Lim, A.H.; Jung, J.A.; Huang, H.-L.A.; Ackerman, S.A.; Otkin, J.A. Assimilation of clear sky atmospheric infrared sounder radiances in short-term regional forecasts using community models. J. Appl. Remote Sens. 2014, 8, 083655. [CrossRef]

30. Schwartz, C.S.; Liu, Z.; Lin, H.-C.; McKeen, S.A. Simultaneous three-dimensional variational assimilation of surface fine particulate matter and MODIS aerosol optical depth. J. Geophys. Res. Atmos. 2012, 117. [CrossRef]

31. Wang, P.; Li, J.; Goldberg, M.D.; Schmit, T.J.; Lim, A.H.; Li, Z.; Han, H.; Li, J.; Ackerman, S.A. Assimilation of thermodynamic information from advanced infrared sounders under partially cloudy skies for regional NWP. J. Geophys. Res. Atmos. 2015, 120, 5469-5484. [CrossRef]

32. Wang, P.; Li, J.; Li, Z.; Lim, A.H.; Li, J.; Schmit, T.J.; Goldberg, M.D. The Impact of Cross-track Infrared Sounder (CrIS) Cloud-Cleared Radiances on Hurricane Joaquin (2015) and Matthew (2016) Forecasts. J. Geophys. Res. Atmos. 2017, 122, 13-201. [CrossRef]

33. Wang, P.; Li, J.; Lu, B.; Schmit, T.J.; Lu, J.; Lee, Y.-K.; Li, J.; Liu, Z. Impact of moisture information from advanced Himawari imager measurements on heavy precipitation forecasts in a regional NWP model. $J$. Geophys. Res. Atmos. 2018, 123, 6022-6038. [CrossRef]

34. Wang, P.; Li, J.; Li, Z.; Lim, A.H.; Li, J.; Goldberg, M.D. Impacts of Observation Errors on Hurricane Forecasts when Assimilating Hyperspectral Infrared Sounder Radiances in Partially Cloudy Skies. J. Geophys. Res. Atmos. 2019, 124, 10802-10813. [CrossRef]

35. Zhang, M.; Zupanski, M.; Kim, M.-J.; Knaff, J.A. Assimilating AMSU-A radiances in the TC core area with NOAA operational HWRF (2011) and a hybrid data assimilation system: Danielle (2010). Mon. Weather Rev. 2013, 141, 3889-3907. [CrossRef]

36. Li, J.; Han, W. A step forward toward effectively using hyperspectral IR sounding information in NWP. Adv. Atmos. Sci. 2017, 34, 1263-1264. [CrossRef]

37. Lee, J.-R.; Li, J.; Li, Z.; Wang, P.; Li, J. ABI water vapor radiance assimilation in a regional NWP model by accounting for the surface impact. Earth Space Sci. 2019, 6, 1652-1666. [CrossRef]

38. Chung, E.-S.; Soden, B.J.; Sohn, B.-J.; Schmetz, J. Model-simulated humidity bias in the upper troposphere and its relation to the large-scale circulation. J. Geophys. Res. 2011, 116, D10110. [CrossRef] 
39. Iacono, M.J.; Delamere, J.S.; Mlawer, E.J.; Clough, S.A. Evaluation of upper tropospheric water vapor in the NCAR Community Climate Model (CCM3) using modeled and observed HIRS radiances. J. Geophys. Res. Atmos. 2003, 108, ACL 1-1-ACL 1-19. [CrossRef]

40. Lim, A.H.N.; Jung, J.A.; Nebuda, S.E.; Daniels, J.M.; Bresky, W.; Tong, M.; Tallapragada, V. Tropical Cyclone Forecasts Impact Assessment from the Assimilation of Hourly Visible, Shortwave, and Clear-Air Water Vapor Atmospheric Motion Vectors in HWRF. Weather Forecast. 2019, 34, 177-198. [CrossRef]

41. Li, Z.; Li, J.; Gunshor, M.; Moeller, S.-C.; Schmit, T.J.; Yu, F.; McCarty, W. Homogenized Water Vapor Absorption Band Radiances From International Geostationary Satellites. Geophys. Res. Lett. 2019, 46, 10599-10608. [CrossRef]

C 2020 by the authors. Licensee MDPI, Basel, Switzerland. This article is an open access article distributed under the terms and conditions of the Creative Commons Attribution (CC BY) license (http://creativecommons.org/licenses/by/4.0/). 